\title{
The Importance of Gestation-Adjusted Birthweight Centile in Assessment of Fetal Growth in Metabolic Conditions
}

\author{
(1) Caroline Ovadia ${ }^{1}$, (1) Hanns-Ulrich Marschall ${ }^{2}$, (1) Catherine Williamson ${ }^{1}$ \\ ${ }^{1}$ King's College London, Department of Women and Children's Health, London, United Kingdom \\ 2University of Gothenburg, Department of Molecular and Clinical Medicine, Gothenburg, Sweden
}

\section{Dear Editor,}

While we welcome the intention of $\mathrm{Li}$ et al. (1) to assess the effect of intrahepatic cholestasis of pregnancy (ICP) upon newborn birthweight, we have concerns about the authors' interpretation of their findings because the birthweights in their meta-analysis were not corrected for gestational week or reported as a customised birthweight centile.

ICP is associated with delivery at an earlier gestational age (2), and this is reported in all of the cited manuscripts contributing to this meta-analysis $(3,4,5,6,7)$. Using the data presented in Table 2 from the manuscript, the mean difference in gestational week of birth for the combined patient cohort of these 5 studies is 1.3 weeks (ICP $37.6 \pm 1.9$, control $38.9 \pm 1.6)$ (1). The authors report a mean difference in birthweight of $175 \mathrm{~g}$ ( $95 \%$ confidence interval 48-301) between ICP and control babies. Between 36 and 40 weeks' gestation, the average weekly increase in birthweight typically exceeds this figuret (8), as shown by the Canadian population data which indicates that for female fetuses the average weekly weight gain is $183 \mathrm{~g}$, whilst for male fetuses the weekly weight gain is 195.75 g.

An accurate birthweight centile should be adjusted taking into consideration the baby's sex, maternal height, weight, parity and ethnic group (9). These data were not reported in the meta-analysis by Li et al (1). However, the study by Martineau et al (6) reports customised birthweight centiles in ICP compared to normal pregnancies. This would be consistent with the reported increased ponderal index of ICP babies reported in the cited manuscript of Cheng et al (4). Thus, despite a lower absolute birthweight (at earlier gestations), the babies of ICP mothers in this study were unlikely to have features of intrauterine growth restriction.

This is consistent with multiple other studies reporting babies of ICP pregnancies to have increased birthweight centiles, including two large population cohorts reporting birthweight centiles of 6146 ICP babies compared with over 1.2 million controls $(10,11)$; in contrast to the 198 (ICP) and 189 (control) babies reported in this meta-analysis (1).

This is of critical relevance to the management of women with ICP. The management of fetuses at risk of small for gestational age necessitates serial growth ultrasound scanning, for which there is no indication in ICP. Conversely, babies who are large for gestational age at birth have a longer-term risk of adverse metabolic health, as has been reported for babies of ICP pregnancies (12). Furthermore, the increased risk of larger fetuses in ICP will influence obstetric advice with regard to the risk of birth dystocia. It may also result in testing affected women for gestational diabetes, which is more prevalent in ICP (13).

We believe this manuscript could mislead affected women and their clinicians. Li et al's (1) findings reflect the fact that babies born to mothers with ICP are typically of a lighter weight secondary to being born at an earlier gestation. However, most studies demonstrate that they are of a greater birth weight centile for gestational week at delivery.

Keywords: Intrahepatic, cholestasis, pregnancy, birthweight, centile 


\section{Ethics}

Peer-review: Internally peer-reviewed.

\section{Authorship Contributions}

Concept: Caroline Ovadia, Analysis or Interpretation: Caroline Ovadia, Hanns-Ulrich Marschall, Catherine Williamson, Literature Search: Caroline Ovadia, Writing: Caroline Ovadia, Hanns-Ulrich Marschall, Catherine Williamson

Financial Disclosure: Work was funded by Tommy's, ICP Support and the NIHR Biomedical Research Centre at Guy's and St Thomas' NHS Foundation Trust and King's College London. The views expressed are those of the authors and not necessarily those of the NHS, NIHR or the Department of Health.

\section{References}

1. Li L, Chen YH, Yang YY, Cong L. Effect of intrahepatic cholestasis of pregnancy on neonatal birth weight: a meta-analysis. J Clin Res Pediatr Endocrinol 2018;10:38-43. Epub 2017 Aug 21

2. Glantz A, Marschall HU, Mattsson LA. Intrahepatic cholestasis of pregnancy: Relationships between bile acid levels and fetal complication rates. Hepatology 2004;40:467-474.

3. Alsulyman OM, Ouzounian JG, Ames-Castro M, Goodwin TM. Intrahepatic cholestasis of pregnancy: perinatal outcome associated with expectant management. Am J Obstet Gynecol 1996;175:957-960.

4. Cheng XY, Zhang LJ, Lin L, Liu J, Ding YL. Relationship of fetal total bile acid and the change of fetal pancreas endocrine secretion and its impact on fetal growth and development in intrahepatic cholestasis of pregnancy. Zhonghua Fu Chan Ke Za Zhi 2009;44:23-26.
5. Kowalska-Kanka A, Maciejewski T, Niemiec KT. The concentrations of bile acids and erythropoietin in pregnant women with intrahepatic cholestasis and the state of the fetus and newborn. Med Wieku Rozwoj 2013;17:232-245

6. Martineau MG, Raker C, Dixon PH, Chambers J, Machirori M, King NM, Hooks ML, Manoharan R, Chen K, Powrie R, Williamson C. The metabolic profile of intrahepatic cholestasis of pregnancy is associated with impaired glucose tolerance, dyslipidemia, and increased fetal growth. Diabetes Care 2015;38:243-248. Epub 2014 Dec 12

7. Ersoy AO, Kirbas A, Ozler S, Ersoy E, Ozgu-Erdinc AS, Ergin M, Erkaya S, Uygur D, Danisman N. Maternal and fetal serum levels of caspase-cleaved fragments of cytokeratin-18 in intrahepatic cholestasis of pregnancy. J Matern Fetal Neonatal Med 2016;29:562-566. Epub 2015 Feb 10

8. Kramer MS, Platt RW, Wen SW, Joseph KS, Allen A, Abrahamowicz M, Blondel B, Bréart G; Fetal/Infant Health Study Group of the Canadian Perinatal Surveillance System. A New and Improved Population-based Canadian Reference for Birth Weight for Gestational Age. Pediatrics 2001;108:35.

9. Gardosi J, Francis A. Customised Weight Centile Calculator. Gestation Network, www.gestation.net

10. Wikström Shemer E, Marschall HU, Ludvigsson JF, Stephansson O. Intrahepatic cholestasis of pregnancy and associated adverse pregnancy and fetal outcomes: a 12-year population-based cohort study. BJOG 2013;120:717-723. Epub 2013 Feb 19

11. Geenes V, Chappell LC, Seed PT, Steer PJ, Knight M, Williamson C. Association of severe intrahepatic cholestasis of pregnancy with adverse pregnancy outcomes: a prospective population-based casecontrol study. Hepatology 2014;59:1482-1491. Epub 2014 Feb 26

12. Papacleovoulou G, Abu-Hayyeh S, Nikolopoulou E, Briz O, Owen BM, Nikolova V, Ovadia C, Huang X, Vaarasmaki M, Baumann M, Jansen E, Albrecht C, Jarvelin MR, Marin JJ, Knisely AS, Williamson C. J Clin Invest 2013;123:3172-3181. Epub 2013 Jun 24

13. Martineau M, Raker C, Powrie R, Williamson C. Intrahepatic cholestasis of pregnancy is associated with an increased risk of gestational diabetes. Eur J Obstet Gynecol Reprod Biol 2014;176:80-85. Epub 2014 Jan 7 